Esta obra está bajo una Licencia Creative Commons Atribución-NoComercial-Compartirlgual 4.0 Internacional

(c) (i) (2)(2)

Poder Trans. Una apuesta a las disidencias sexuales a través de la historieta latinoamericana

Álvaro Javier Marrocco

DOI: https://doi.org/10.24215/16696581e274

\title{
Poder Trans. Una apuesta a las disidencias sexuales a través de la historieta latinoamericana
}

\section{Trans Power. A bet on sexual dissent through the Latin American comic}

\author{
Álvaro Javier Marrocco alvaromarrocco@gmail.com \\ https://orcid.org/0000-0003-3011-0166 \\ Universidad Nacional de Rosario, Argentina
}

\section{Resumen}

El siguiente trabajo presenta una reseña crítica de la antología Poder Trans. Historieta Latinoamericana (Editorial Municipal de Rosario, 2019). Una cuidada y diversa selección de 22 historietas de temática trans seleccionadas durante una convocatoria latinoamericana realizada en 2018, en conjunto con la Dirección de Diversidad Sexual. La obra se constituye 
colectivamente como el resultado de una convocatoria latinoamericana realizada en 2018. La antología, coordinada por José Sainz, y un jurado integrado por Laerte, el Licenciado en Artes Audiovisuales por la Universidad Nacional de La Plata e investigador Lucas Morgan, junto a Cecilia Estalles, Magalí Muñiz, Cecilia Saurí, Carla Pericles y representantes del Archivo de la Memoria Trans.

Palabras Clave: historieta; diversidad sexual; educación; cultura; comic.

\section{Abstract}

The following work presents a critical review of the anthology Power Trans.

Latin American Cartoon (Editorial Municipal de Rosario, 2019) is a careful and diverse selection of 22 trans-themed

comics selected during a Latin American call held in 2018, in conjunction with the Directorate of Sexual Diversity.

The work is collectively constituted as the result of a Latin American call held in 2018.

The anthology, coordinated by José Sainz, and a jury composed of Laerte, the Bachelor of Audiovisual Arts from the National

University of La Plata and researcher Lucas Morgan, together with Cecilia Estalles, Magalí Muñiz, Cecilia Saurí,

Carla Pericles and representatives of the Trans Memory Archive.

Keywords: comic strip; sexual diversity; education; cultura; comic

La antología Poder Trans. Historieta Latinoamericana reúne a un sinfín de artistas visuales, activistas disidentes, guionistas gráficos, ilustradores, historietistas e investigadores quienes trazan un mapa latinoamericano amplio, experiencial y educativo, logrando componer un estado de situación que va de lo particular de las historias personales a las vinculaciones sociales, poniendo en escena las problemáticas de las comunidades trans latinoamericanas. 
La ilustración de tapa le pertenece al activista Jovan Israel (Ciudad de México, 1991), que recorre tapa y contratapa sobre un apacible color rosa y en cuya ilustración se ve a una mujer gigante con un tatuaje en su pecho que dice Jefita -todo un gesto-, recostada sobre una ciudadela en donde los autos y los transeúntes son pequeños y difusos, no así, las inscripciones que indican: "ya no me destruyas, ya dejen de matarnos, las identidades no binarias existen».

En la parte interior del libro y en forma de prólogo dice: «Contra la discriminación hacia los cuerpos y las identidades disidentes, en particular de las personas trans, travestis, transexuales y transgénero, históricamente excluidas mediante violencia física, simbólica, psicológica, sexual y económica del sistema educativo, de salud y de trabajo formal. Por la visibilización de sus cotidianidades, producciones, circuitos de sociabilidad y de todo elemento que apunte a producir un registro más acabado de cuál es la situación que atraviesan las comunidades trans latinoamericanas y de la singularidad de sus historias personales».

El libro abre con una historieta de transfemicidio y cierra con otra de violencia callejera, en el medio conviven una diversidad de narraciones como la historieta documental, la de denuncia, registros de escenas de intimidad, de transmasculinidades, de feminidades trans, de secuencias estéticas y de secuencias narrativas, informes sobre el pasado y el presente, viñetas en blanco y negro, en colores o monocromáticas

Los abordajes propuestos por los artistas latinoamericanos que son parte de la compilación, exploran fronteras geográficas, sexuales, experienciales e informativas. Entre ellos vale destacar la inclusión de cinco historietistas de Brasil: Anilina de Lino Arruda, Reflexões de Ellie Irineu, Tretinhas de Lázaro, Acuenda esse pajubá! de Isadora Simões / Lays Cunha y Nossa bandeira jamais será vermelha de Mário César. Todos ellos logran poner en escena las tensiones, inequidades y violencias que viven en Brasil estos colectivos disidentes en tiempos de intolerancia a lo distinto.

En la tira grafica titulada Chuquichinchay de la colectiva transfeminista peruana No Tengo Miedo se revisan de forma escueta, diversos episodios en temporalidades distintas aunque sin solución de continuidad (desde la Conquista Española hasta el presente) e incluye, de forma pedagógica, mitos incaicos, persecuciones de sodomía, batallas legislativas y violentos mariconicidios.

Las obras reunidas se abren cada una con su propio estilo: diferentes materiales, colores, formas, voces, trazos, rasgos, representaciones. Así la compilación crea un mapa corpóreo donde la convivencia en la divergencia se hace posible. Así como también vale destacar que a diferencia de gran parte de las novelas gráficas de este tipo, incluye una gama de experiencias 
que van del retrato intimista a la infografía, desde las secuencias de aventura a la poesía visual, de la pasión por los monstruos gigantes hasta la seducción animal.

Renglón aparte merecen las incursiones de los artistas santafesinos, Gaspar Aguirre (Reconquista, 1986), Clara Esborraz (Rafaela, Santa Fe, 1991) y María Eugenia Ludueña (Santa Fe, 1969). Gaspar Aguirre, diseñador gráfico graduado en la Universidad Nacional del Nordeste, participa en esta antología con la historieta titulada Psicopompo que remite a aquella frase de Lohana Berkins: «en un mundo de gusanos capitalistas, hay que tener coraje para ser mariposa», donde narra la transición, de la oruga a la mariposa a través de una metáfora. Poniendo en escena como el odio muchas veces se disfraza de cordero, dejando entrever el miedo de lo diferente.

Por su parte, Clara Esborraz, Licenciada en Bellas Artes por la Universidad Nacional de Rosario, participa con la historieta titulada Felices 27 vidas con sus respectivas muertes en donde pone en escena el transformismo y la idea del cambio de rol, para asumir nuevas formas de asumirse. El transformismo o lo transexual, se ve ejemplificado a través de la peluca. La idea de traspaso de pelo como traspaso de poder está presente en Felices 27 vidas con sus respectivas muertes y en la historia drag y trans. Elementos fetiches posibilitadores de transformación sexual. La peluca como un símbolo que posibilita ser otro, que pueda jugar a ser de otra manera, como un desplazamiento, una transformación.

Y por último vale destacar la historieta titulada Diana Sacayán fue un travesticidio, de la santafesina María Eugenia Ludueña con ilustraciones de Florencia Capella y guión de Ana Fornaro, quienes en formato de comic desarrollaron la cobertura del juicio por el travesticidio de Diana Sacayán.

Este trabajo también puede leerse en otra clave: Poder Trans es una antología de comics contra la discriminación y a favor de las historietas de disidencias en el mercado del comic. Desde la Editorial Municipal y la Dirección de Diversidad Sexual de la ciudad de Rosario, ejecutaron una temática distinta, educativa y pedagógica para poder pensar a la industria del entretenimiento por fuera de lo heterocentrado, evitando etiquetas y encasillamientos, y construyendo un espacio en donde se cuentan historias de los que menos representación tienen en la sociedad.

Poder trans tiene como antecedente otra antología, Historieta LGBTI (2017), también publicada por la Dirección de Diversidad Sexual y la Editorial Municipal de Rosario, y se inscribe en una creciente y necesaria producción cultural de la comunidad travesti y trans argentina, que habilita desde la historieta disidente, y otras producciones narrativas, ese espacio rupturista que asoma con un lenguaje y una narrativa pedagógica y educativa distinta, posibilitando y abriendo el juego a lo distinto, y apostando a las disidencias sexuales. 


\section{Referencia bibliográfica}

Poder Trans. Historieta Latinoamericana. Rosario, Editorial Municipal de Rosario, 2019. 